\title{
Development and Validation of a Stability-Indicating High Performance Thin Layer Chromatography (HPTLC) Method for estimation of Canagliflozin in bulk and Pharmaceutical Dosage Form
}

\author{
Ishpreet Kaur $^{1 *}$, Sharad Wakode ${ }^{2}$, Harsharan Pal Singh ${ }^{3}$ \\ ${ }^{1}$ Department of Quality Assurance, Delhi Institute of Pharmaceutical Sciences \& Research, Pushp Vihar, New Delhi, India. ${ }^{2}$ Department of Pharmaceutical \\ Chemistry, Delhi Institute of Pharmaceutical Sciences \& Research, Pushp Vihar, New Delhi, India. ${ }^{3}$ Institute of Food Processing Technology, Conestoga \\ College Institute of Advanced Learning, Kitchener, Ontario, Canada.
}

\begin{tabular}{l}
\hline ARTICLE INFO \\
\hline Article history: \\
Received on: 30/01/2016 \\
Revised on: 13/03/2016 \\
Accepted on: 06/04/2016 \\
Available online: 28/05/2016 \\
\hline Key words: \\
Canagliflozin, \\
Chromatographic separation, \\
Forced Degradation, Method \\
development, Validation.
\end{tabular}

\section{INTRODUCTION}

Canagliflozin is an oral selective Sodium-Glucose cotransporter 2 (SGLT2) inhibitor used for the management of type 2 Diabetes Mellitus (Elkinson et al., 2013). The chemical name (IUPAC) of Canagliflozin is (2S,3R,4R,5S,6R)-2-\{3[5-(4-fluoro-phenyl)-thiophen-2-ylmethyl]-4-methyl-phenyl $\}$-6hydroxymethyltetrahydro-pyran-3,4,5-triol with molecular formula $\mathrm{C}_{24} \mathrm{H}_{25} \mathrm{FO}_{5} \mathrm{~S}$. It is white to off white solid with melting point of $95-105^{\circ} \mathrm{C}$. It is soluble in many organic solvents (methanol, Dimethyl sulfoxide) but insoluble in aqueous media.

\footnotetext{
* Corresponding Author

Ishpreet Kaur, M.Pharm Research Scholar Department of Quality Assurance Delhi Institute of Pharmaceutical Science and Research (DIPSAR) Govt. of NCT of Delhi Pushp Vihar, Sector III, M.B.Road, New Delhi-110 017, India.Email: ishpreet1992@gmail.com
}

It curbs the transporter protein SGLT2 present in the proximal tubules of the kidney which curtails renal glucose absorption, thereby increasing urinary glucose excretion and lowering blood glucose levels.

It is a product of Mitsubishi Tanabe Pharma and Janssen Pharmaceuticals, a division of Johnson and Johnson (Neumiller et al., 2010; Singh et al., 2015; Song et al., 2014). As per the Literature Survey, it is revealed that the drug has been estimated by Liquid chromatography (Iqbal et al., 2015) and Ultra High Performance Liquid Chromatography-Mass Spectroscopy (UHPLC-MS) (Iqbal et al., 2015) in biological fluids like human and rat plasma. Bulk drug and its marketed formulation has been analyzed by Ultraviolet Spectroscopic but no High Performance thin layer Chromatography analysis has been reported for the estimation in bulk and pharmaceutical dosage forms (Kaur et al., 2015) 
The aim and objective of the present work was to develop and validate a stability indicating simple, precise, sensitive high performance thin layer chromatography method for Canagliflozin in its bulk and tablet dosage form and validate as per International Conference on Harmonization (ICH) Q2 (R2) guidelines. (Validation of Analytical Procedures: Text and Methodology Q2 (R1), Geneva, 2005)

\section{MATERIALS AND METHODS}

\section{Instrumentation}

The HPTLC system (CAMAG, Switzerland) consisted of Linomat $\mathrm{V}$ auto sampler connected to a nitrogen cylinder, a twin trough chamber $(20 \times 10 \mathrm{~cm})$, a derivatisation chamber, a plate heater, TLC Scanner IV (Camag Muttenz, Switzerland), UV cabinet with dual wave length UV lamps and win CATS software were used for chromatographic study. Electronic analytical balance (Shimadzu AUX-220) was used for all the weighing purpose.

\section{Chemicals and reagents}

Analytically pure sample of Canagliflozin was obtained from Xi'an Kingsmart Group Co. Limited, Xi'an City, China and tablet formulation $\left(\right.$ INVOKANA $^{\circledR}$ ) was procured from Johnson \& Johnson, New Delhi, India with labelled claim of $100 \mathrm{mg}$. Methanol was obtained from MERCK, Germany. Analytical reagent grade of Toluene and Ethyl acetate were purchased from Rankem, Mumbai, India.

\section{Chromatographic conditions}

Stationary phase:Precoated silica gel $60 \mathrm{~F}_{254}$ HPTLC aluminium plates $(20 \times 10 \mathrm{~cm}, 0.2 \mathrm{~mm}$ thick $)$.

Mobile phase: Toluene: Ethyl acetate: Methanol (2:2:1). Saturation time: 30 minutes.

Wavelength: $290 \mathrm{~nm}$.

Lamp: Deuterium

The HPTLC analysis was performed on Pre-coated Silica Gel $60 \mathrm{~F}_{254}$ HPTLC plates $(20 \times 10 \mathrm{~cm}$, layer thickness $0.2 \mathrm{~mm}(\mathrm{E}$. Merck KGaA, Darmstadt, Germany). HPTLC plates were prewashed with $10 \mathrm{~mL}$ of methanol and activated at $80^{\circ} \mathrm{C}$ for $5 \mathrm{~min}$ before application of sample. The standard and formulation samples of Canagliflozin were spotted using a Linomat 5 auto sampler fitted with a $100 \mu \mathrm{L}$ Hamilton syringe (CAMAG, Muttenz, Switzerland) and operated with settings of a band length of $3.5 \mathrm{~mm}$; band distance of $7.2 \mathrm{~mm}$; distance from the side of plate of $10 \mathrm{~mm}$; and distance from the bottom of the plate of 10 $\mathrm{mm}$. The plates were developed to a distance of $70 \mathrm{~mm}$ in a mobile phase consisting of Toluene: Ethyl acetate: Methanol (2:2:1 v/v/v) and development was carried out in twin trough chamber $(20 \times 10$ $\mathrm{cm})$ presaturated with the mobile phase. The developed HPTLC plates were air dried and densitometric scanning was performed on CAMAG TLC scanner III in absorbance mode equipped with WINCATS planar chromatography manager (version 1.4.6) software. The spots were analyzed at a wavelength of $290 \mathrm{~nm}$. The scanning of the spots was done at a rate of $20 \mathrm{~mm} / \mathrm{s}$. Evaluation was performed using linear regression analysis via peak areas.

\section{Preparation of solutions \\ Preparation of stock solution}

Accurately weighed quantity of Canagliflozin $(10 \mathrm{mg})$ was transferred to a $10 \mathrm{ml}$ volumetric flask, dissolved and diluted up to the mark with methanol (Concentration:1000 $\mu \mathrm{g} / \mathrm{ml})($ Skoog DA et al.,2007).

\section{Preparation of standard working solution}

It was prepared by taking $0.1 \mathrm{ml}$ of stock solution into 1 $\mathrm{ml}$ volumetric flask and the final volume was made up with $0.9 \mathrm{ml}$ of methanol (100 $\mu \mathrm{g} / \mathrm{ml})$ (Skoog DA et al.,2007).

\section{Preparation of mobile phase}

The mobile phase was prepared by mixing Toluene, Ethyl acetate and Methanol in the ratio of 2:2:1 v/v/v.

\section{Preparation of sample solution for Force degradation studies}

To assess the stability indicating property of the developed HPTLC method, stress studies were carried out under ICH recommended conditions. Forced degradation of Canagliflozin was carried by exposing the bulk sample to acidic, alkaline, oxidative, photolytic, dry heat and neutral conditions. The aim was to study the ability of the proposed method to measure the analyte response in presence of its degradation products (Rajput DK et al., 2013).

\section{Acid and alkali hydrolysis}

Aliquot of $1 \mathrm{ml}$ of Canagliflozin solution $(10 \mathrm{mg}$ dissolved in $10 \mathrm{ml}$ i.e. $1 \mathrm{mg} / \mathrm{ml}$ ) was transferred to a small round bottom flask and it was mixed with $9 \mathrm{ml}$ of $0.1 \mathrm{~N}$ hydrochloric acid or $0.1 \mathrm{~N}$ sodium hydroxide. The prepared solutions were subjected to reflux for $2 \mathrm{~h}$ in a boiling water bath. The samples were cooled to room temperature $\left(25^{\circ} \mathrm{C}\right)$, neutralized with an amount of acid or base equivalent to that of the previously added. From the resulting neutral solution, $5 \mu 1 /$ spot was applied at TLC plate with the help of applicator.

\section{Oxidation}

Aliquot of $1 \mathrm{ml}$ of Canagliflozin solution (10 $\mathrm{mg}$ dissolved in $10 \mathrm{ml}$ i.e. $1 \mathrm{mg} / \mathrm{ml}$ ) was transferred to round bottom flask and it was mixed with $9 \mathrm{ml}$ of $30 \%$ hydrogen peroxide solution, the reaction mixture was allowed to proceed at room temperature $\left(25^{\circ} \mathrm{C}\right)$ for $2 \mathrm{~h}$ with intermittent shaking. A volume of $5 \mu \mathrm{l} / \mathrm{spot}$ was applied at TLC plate with the help of applicator.

\section{Irradiation with ultraviolet light}

A sample powder of Canagliflozin $(10 \mathrm{mg}$ ) was exposed to UV light $(254 \mathrm{~nm})$ for $48 \mathrm{~h}$. The material was dissolved in 10 $\mathrm{ml}$ water. The solution was claimed to have concentration of 1 $\mathrm{mg} / \mathrm{ml}$. A volume of $5 \mu \mathrm{l} / \mathrm{spot}$ was applied at TLC plate with the 
help of applicator. As well as, an aqueous solution of Canagliflozin $(1 \mathrm{mg} / \mathrm{ml})$ was exposed to UV light $(254 \mathrm{~nm})$ for 48 $\mathrm{h}$, and after that a volume of $5 \mu \mathrm{l} / \mathrm{spot}$ was applied at TLC plate with the help of applicator.

\section{Thermal degradation}

A sample powder of Canagliflozin $(10 \mathrm{mg})$ was exposed to a temperature of $70^{\circ} \mathrm{C}$ for $48 \mathrm{~h}$ in hot air oven. The material was dissolved in $10 \mathrm{ml}$ methanol. The solution was claimed to have concentration of $1 \mathrm{mg} / \mathrm{ml}$. A volume of $5 \mu \mathrm{l} / \mathrm{spot}$ was applied at TLC plate with the help of applicator.As well as, an aqueous solution of Canagliflozin $(1 \mathrm{mg} / \mathrm{ml})$ was exposed to a temperature of $70^{\circ} \mathrm{C}$ for $48 \mathrm{~h}$, and after that a volume of $5 \mu \mathrm{l} / \mathrm{spot}$ was applied at TLC plate with the help of applicator.

\section{Preparation of sample solution for assay of marketed formulations}

Twenty INVOKANA ${ }^{\circledR}$ tablets were weighed, average weight was calculated, and were triturated to fine powder. A powder proportionate to $10 \mathrm{mg}$ was taken in a $10 \mathrm{ml}$ volumetric flask to which meager amount of methanol was added. The flask is then ultra-sonicated for 15 minutes and volume is made up with methanol. The tablet solution is then filtered through whatman filter paper (No.41) and from the above solution, $1 \mu \mathrm{l}$ of solution containing 1000ng/band was applied on the HPTLC plate with the help of Linomat $\mathrm{V}$ auto sprayer in 3 replicates. The plate was developed and studied under earlier expressed chromatographic conditions.

\section{Analysis of forced degradation samples}

Analysis of the degraded sample solutions was done by applying $5 \mu \mathrm{l}$ with the help of auto sampler to same TLC plate in duplicate. The plate was developed, dried and analyzed as described earlier in chromatographic conditions.

\section{Preparation of Calibration Curve}

Aliquots of $0.1,0.2, \quad 0.4, \quad 0.5,1,2,4$ and $5 \mu \mathrm{l}$ of standard working solution of Canagliflozin were spotted on HPTLC plate using $100 \mu \mathrm{L}$ Hamilton syringe with the help of Linomat $\mathrm{V}$ auto sprayer to obtain a concentration of 10$500 \mathrm{ng} / \mathrm{spot}$. The plate was developed, dried and analyzed at $290 \mathrm{~nm}$ with the help of TLC Scanner 3 using Win-CATS software.

Sets of calibration curves were constructed and the area report was recorded. A plot of concentration versus area under curve was established (10-500 ng/spot).

\section{RESULTS AND DISCUSSION}

\section{Analytical Method Validation}

The developed method was validated for different parameters like linearity, precision, accuracy, specificity, ruggedness, robustness, LOD and LOQ as per ICH Q2A and Q2B guidelines (Validation of Analytical Procedures: Text and Methodology Q2 (R1), Geneva, 2005).

\section{Linearity}

Linear regression data over the range of $10-500 \mathrm{ng} / \mathrm{spot}$ for Canagliflozin with a correlation coefficient of 0.9988 unfolds good linear relationship between area and concentration in calibration curve. Figure 1 presents calibration curve of Canagliflozin whereas Figure 2 and 3 displays Chromatograms of different Aliquots and overlay chromatograms of different aliquots at $290 \mathrm{~nm}$.

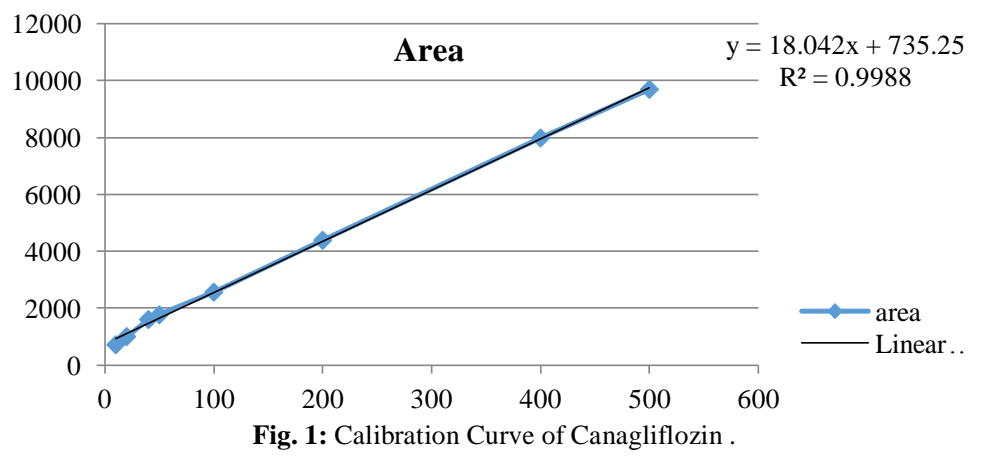

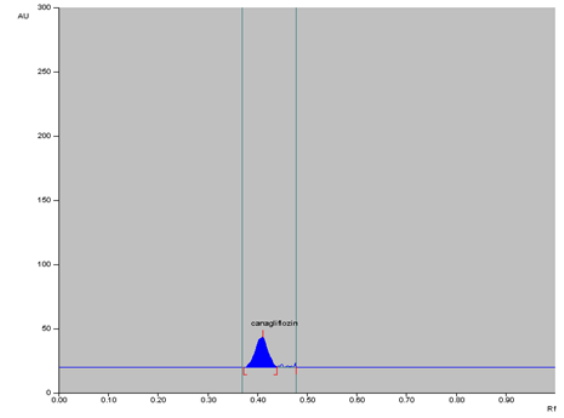

A-Chromatogram showing 10ng/spot at $290 \mathrm{~nm}$

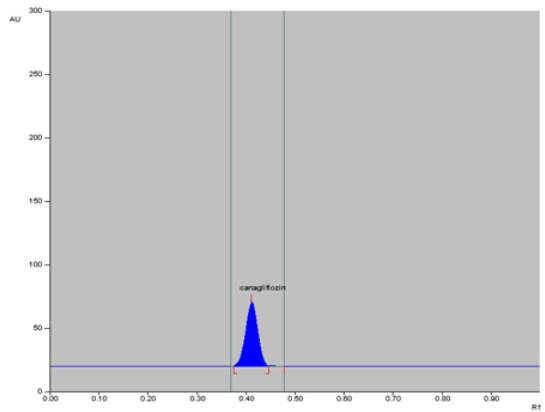

B- showing 20ng/spot at 290nm

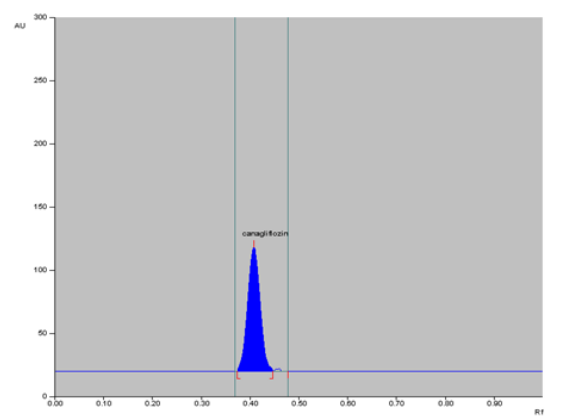

C-Chromatogram showing 40ng/spot at 290nm 


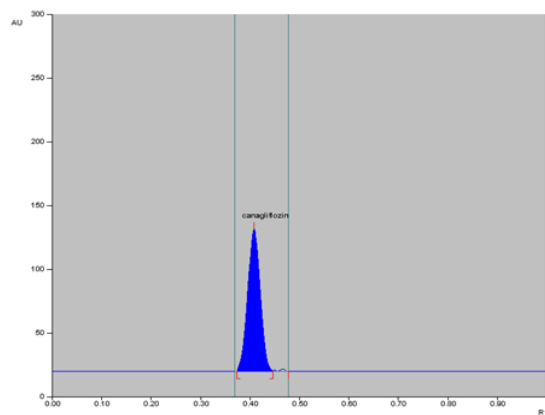

D-Chromatogram showing 50ng/spot at 290nm

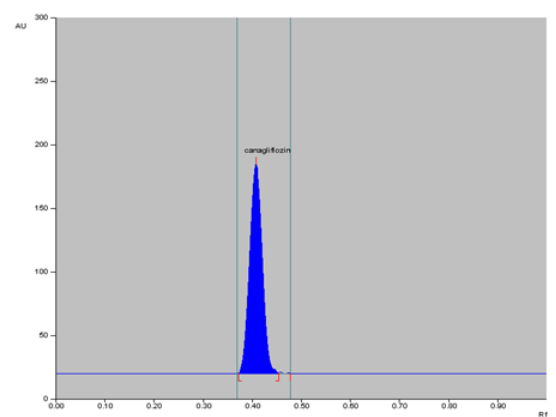

E-Chromatogram showing 100ng/spot at 290nm

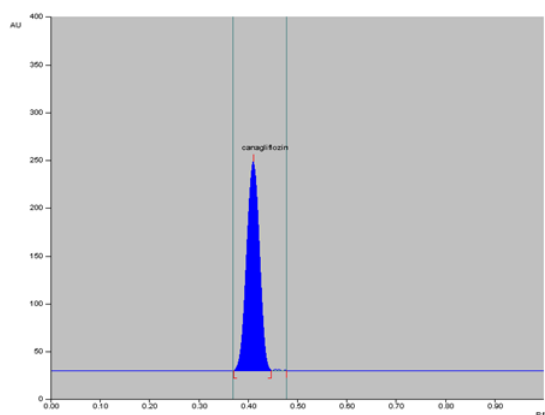

F-Chromatogram showing 200ng/spot at 290nm

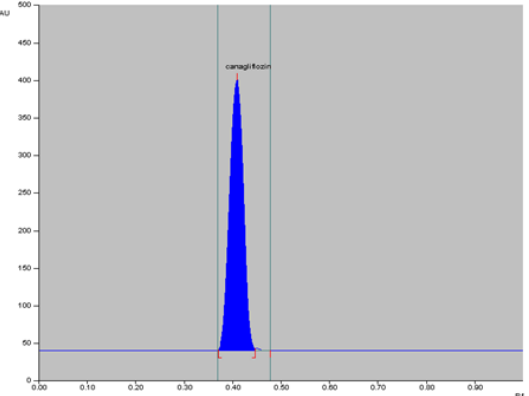

G-Chromatogram showing 400ng/spot at 290nm

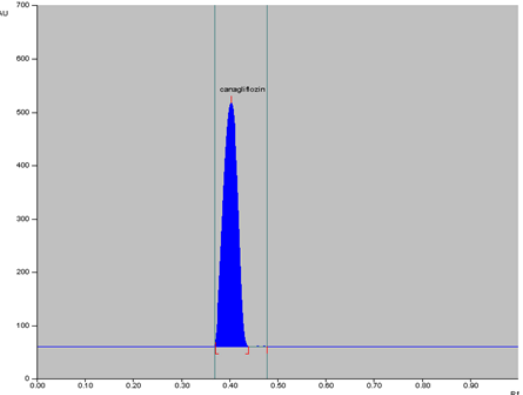

H-Chromatogram showing 500ng/spot at 290nm

Fig. 2: Chromatograms (A-H) of different Aliquots at 290nm.

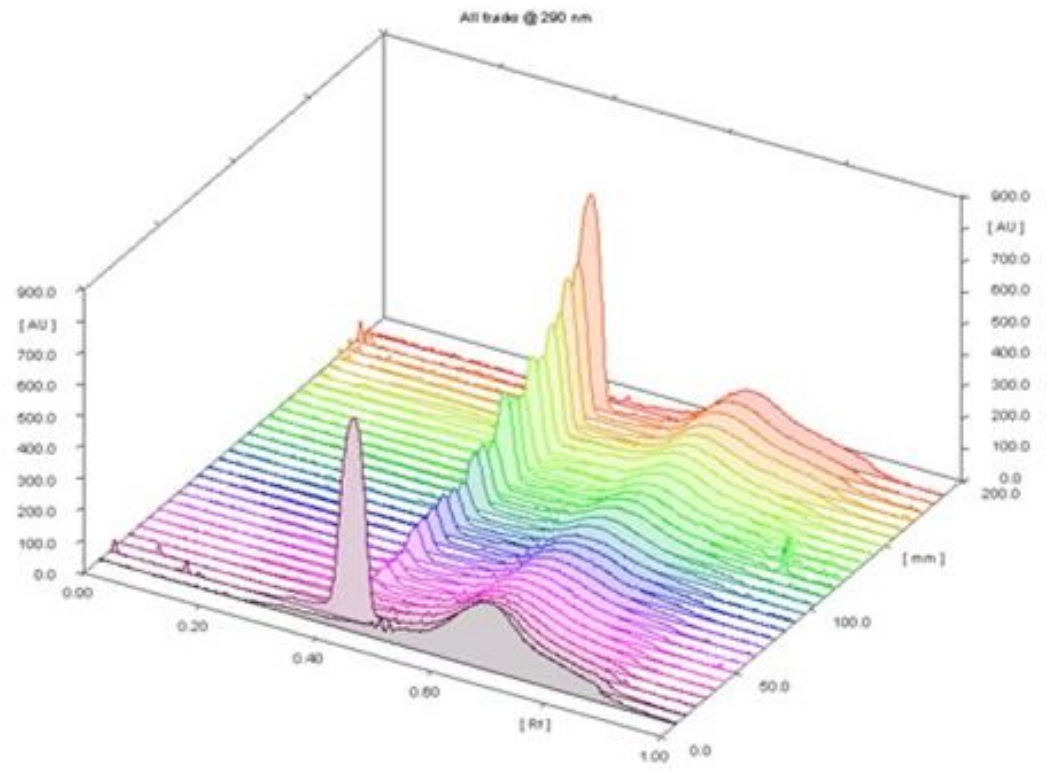

Fig. 3: Overlay Chromatograms of different aliquots at $290 \mathrm{~nm}$.

Table 1: Accuracy Studies of Canagliflozin.

\begin{tabular}{|c|c|c|c|c|}
\hline $\begin{array}{c}\text { Amount of sample taken } \\
\text { (ng/spot) }\end{array}$ & $\begin{array}{c}\text { Amount of standard added } \\
\text { (ng/spot) }\end{array}$ & Percentage of Standard added & \% Recovery & $\begin{array}{c}\text { \% Relative Standard } \\
\text { Deviation }\end{array}$ \\
\hline 100 & 50 & 50 & 99.04 & 0.06 \\
\hline 100 & 100 & 100 & 99.82 & 0.05 \\
\hline 100 & 150 & 150 & 99.49 & 0.04 \\
\hline
\end{tabular}

*Average of three determinations $(n=3)$

\section{Accuracy}

Accuracy of the method was resolved by standard addition method in which standard addition of pure API at three different concentration levels of $50 \%, 100 \%$ and $150 \%$ was performed in triplicate. Table 1 presents accuracy of the method in the terms of $\%$ recovery of the API. 


\section{Precision}

Precision of the method was determined by evaluating intraday and interday precision. Intra-day and Inter-day variation was analyzed by selecting three concentrations which were 20, 100 and 400ng from linearity range. Intraday analysis was carried on same day whereas Interday analysis was carried on three different days in replicates of three. The respective peak areas for different concentrations were reported .Table $2 \& 3$ express precision data for the method in terms of $\%$ RSD.

Table 2: Intra-day Precision Studies of Canagliflozin.

\begin{tabular}{lll}
\hline $\begin{array}{c}\text { Amount of Standard } \\
\text { taken (ng/spot) }\end{array}$ & Peak Area (mAU) & $\begin{array}{c}\text { \% Relative } \\
\text { Standard Deviation }\end{array}$ \\
\hline Day-1 (Morning) & 998 & 0.2 \\
20 & 2562.43 & 0.08 \\
100 & 7983.33 & 0.01 \\
400 & & \\
Day-1 (Afternoon) & 997 & 0.1 \\
20 & 2562.8 & 0.08 \\
100 & 7983.62 & 0.02 \\
400 & & \\
Day-1 (Evening) & 998.33 & 0.15 \\
20 & 2562.15 & 0.08 \\
100 & 7983.19 & 0.01 \\
400 & & \\
\hline
\end{tabular}

Table 3: Inter-day Precision Studies of Canagliflozin.

\begin{tabular}{ccc}
\hline $\begin{array}{c}\text { Amount of Standard } \\
\text { taken (ng/spot) }\end{array}$ & Area (mAU) & $\begin{array}{c}\text { \% Relative Standard } \\
\text { Deviation }\end{array}$ \\
\hline $\begin{array}{c}\text { Day-1 } \\
20\end{array}$ & 997.60 & 0.2 \\
100 & 2561.39 & 0.08 \\
400 & 7982.46 & 0.01 \\
Day-2 & & \\
20 & 996.18 & 0.10 \\
100 & 2563.46 & 0.06 \\
400 & 7983.33 & 0.01 \\
Day-3 & & \\
20 & 995.47 & 0.09 \\
100 & 2563.55 & 0.07 \\
400 & 7983.86 & 0.02 \\
\hline
\end{tabular}

\section{Specificity}

The specificity of the method was evaluated by separating the peaks of both tablet and API. The spot of

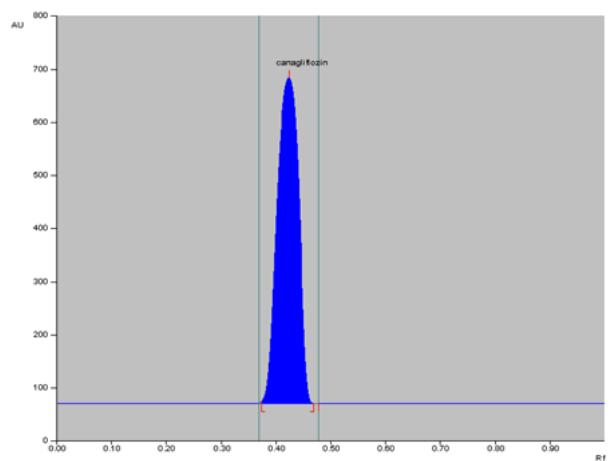

Fig. 4: Chromatogram of Canagliflozin Tablets $\left(\right.$ INVOKANA ${ }^{\circledR}$ ) showing $R_{f}=$ 0.44 .

Canagliflozin in the sample was proved by matching the $\mathrm{R}_{\mathrm{f}}$ and spectra of the standard spot. Therefore, the method was considered to be specific. Figure 4 shows the chromatogram of Canagliflozin tablets.

\section{Robustness}

Robustness of the method was ascertained by deliberately altering the chromatographic conditions. A change in the mobile phase composition and change in wavelength were selected as parameters and were varied separately whereas all other conditions were held constant as described in the method. No difference was observed in the peak area and $R_{\mathrm{f}}$ values. Table 4 indicates robustness of the method.

Table 4: Robustness studies of Canagliflozin.

\begin{tabular}{lcc}
\multicolumn{1}{c}{ Parameter } & Area (mAU) & $\begin{array}{c}\text { \% Relative } \\
\text { Standard } \\
\text { Deviation }\end{array}$ \\
\hline $\begin{array}{l}\text { Change in Solvent system } \\
\text { Toluene: Ethyl Acetate: Methanol } \\
(3: 1: 1)\end{array}$ & 2561.70 & 0.06 \\
$\begin{array}{l}\text { Toluene: Ethyl Acetate: Methanol } \\
(2: 1: 3)\end{array}$ & 2562.34 & 0.05 \\
$\begin{array}{l}\text { Change in Wavelength }( \pm 2 \mathrm{~nm}) \\
288 \mathrm{~nm}\end{array}$ & 2564.32 & \\
$292 \mathrm{~nm}$ & 2562.50 & 0.05 \\
\end{tabular}

\section{Ruggedness}

Ruggedness of the method was performed by carrying out the method with the help of two different analysts. Table 5 explains the ruggedness of the method in terms of $\%$ RSD.

Table 5: Ruggedness studies of Canagliflozin.

\begin{tabular}{ccc}
\hline Analyst & Area $(\mathbf{m A U})$ & $\begin{array}{c}\text { \% Relative Standard } \\
\text { Deviation }\end{array}$ \\
\hline Analyst 1 & 2563.79 & 0.06 \\
Analyst 2 & 2563.62 & 0.07 \\
\hline
\end{tabular}

\section{Detection limit and Quantification Limit}

A limit of detection (LOD) and a limit of quantification (LOQ) were calculated according to the formula:

$\mathrm{LOD}=3.3 \sigma / \mathrm{s}$

$\mathrm{LOQ}=10 \sigma / \mathrm{s}$

Where, ' $\sigma$ ' is the standard deviation of ' $y$ ' intercept of regression line and ' $s$ ' is the slope of the calibration curve.

The LOD and LOQ values were found to be 0.39 and 1.19 respectively

\section{Assay of the Pharmaceutical Dosage Form}

Table 6 displays that the \%Mean recovery in formulation is 99.8 and \%relative standard deviation is less than $2 \%$ which is within the limits. Figure 5 represents chromatogram of INVOKANA $^{\circledR}$.

Table 6: Assay of Canagliflozin Tablets (INVOKANA ${ }^{\circledR}$ ).

\begin{tabular}{lccc}
\hline Formulation & $\begin{array}{c}\text { Labelled } \\
\text { claim }\end{array}$ & $\begin{array}{c}\text { Amount } \\
\text { found (\%)* }\end{array}$ & $\begin{array}{c}\text { \% Relative Standard } \\
\text { Deviation }\end{array}$ \\
\hline INVOKANA $^{\circledR}$ & $100 \mathrm{gm}$ & 99.8 & 0.02 \\
\hline *Average of three determinations & &
\end{tabular}




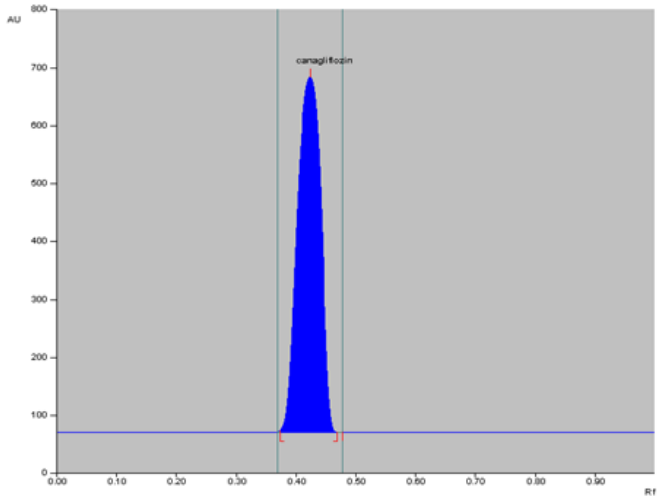

Fig. 5: Chromatogram of Canagliflozin Tablets (INVOKANA $\left.{ }^{(}\right)$).

\section{Analysis of forced degradation samples of Canagliflozin}

From this forced degradation, it was clear that in case of thermal stability Canagliflozin was most stable under the employed stress conditions as shown in table 7. In case of acid hydrolysis, alkaline hydrolysis and oxidation degradation was observed and is shown in the respective chromatograms but maximum degradation was seen on irradiation with U.V. light. Nonetheless, the method was able to separate isolate the degradation products from the intact drug.

Table 7: Stability studies of Canagliflozin

\begin{tabular}{lccc}
\hline \multicolumn{1}{c}{ Sample } & $\begin{array}{c}\text { Concentration } \\
\text { Used } \\
(\boldsymbol{\mu g} / \mathbf{s p o t})\end{array}$ & $\begin{array}{c}\text { Concentration left } \\
\text { after degradation } \\
(\boldsymbol{\mu} \mathrm{g} / \mathrm{spot})\end{array}$ & $\begin{array}{c}\% \\
\text { Recovery }\end{array}$ \\
\hline Acid Hydrolysis & 200 & 152.46 & 76.23 \\
Alkaline Hydrolysis & 200 & 159.68 & 79.84 \\
Oxidation & 200 & 143.78 & 71.89 \\
Thermal & 200 & 169.04 & 84.52 \\
Photolytic & 200 & 147.28 & 73.64 \\
\hline
\end{tabular}

This confirmed the stability indicating property of the developed method. The concentration of the produced degradation products analogous to the intact Canagliflozin was determined and found to be $23.77 \%, 20.16 \%, 28.11 \%, 26.36 \%, 16.24 \%$ in case of acid hydrolysis, alkaline hydrolysis ,oxidation, photolytic and thermal stability respectively as shown in Table 7.Figure 6 presents chromatograms showing forced degradation of Canagliflozin.

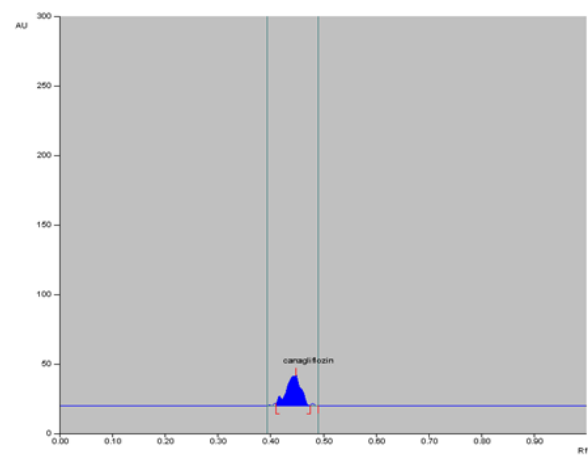

1-Chromatogram of Acid treated Canagliflozin.

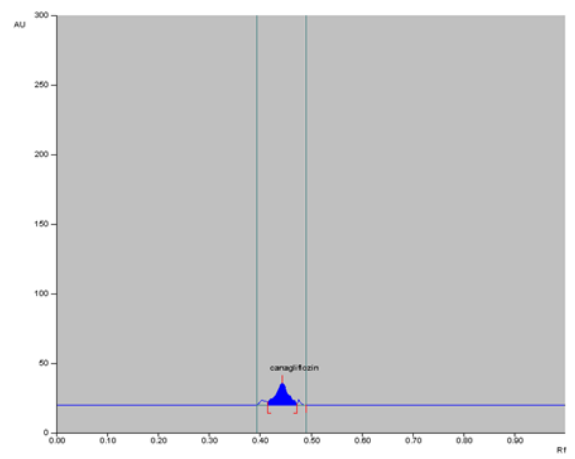

2-Chromatogram of Alkali treated Canagliflozin.

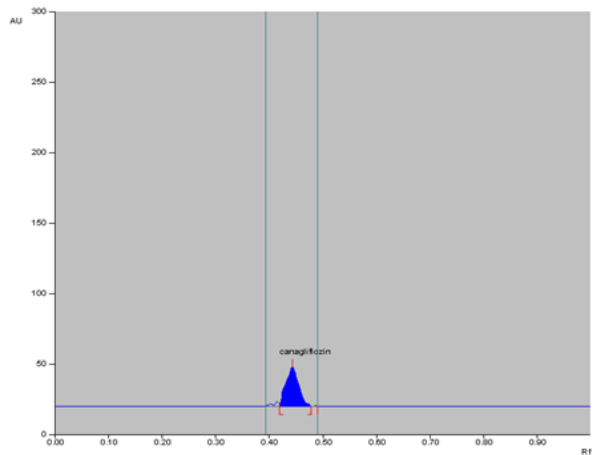

3-Chromatogram of Hydrogen Peroxide treated (Oxidative degradation) Canagliflozin.

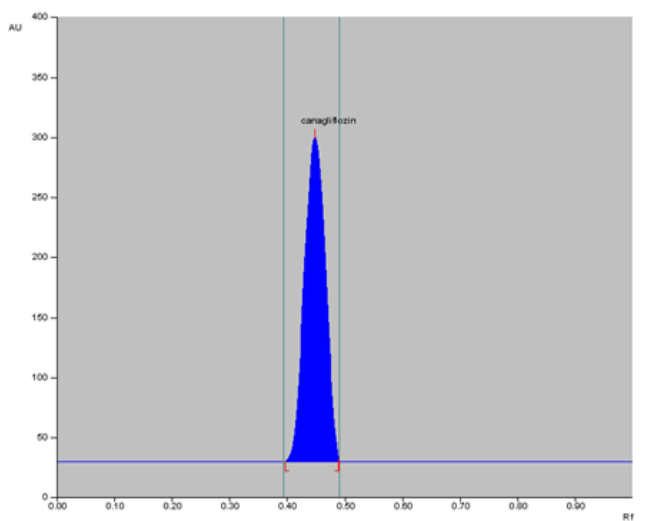

4-Chromatogram of Thermally treated Canagliflozin.

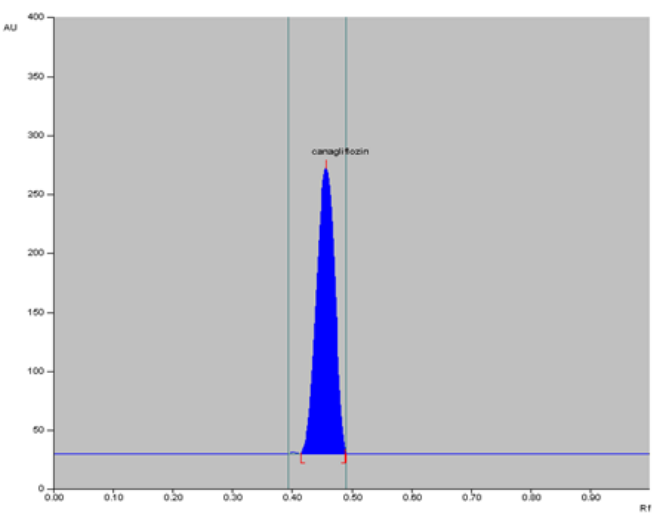

5-Chromatogram of Photo treated Canagliflozin.

Fig. 6: Chromatograms (1-5) showing Forced Degradation of Canagliflozin 
The method explained in the current work provides an agreeable, definite and meticulous way for analysis of Canagliflozin in bulk and pharmaceutical dosage form by high performance thin layer chromatography (Table 7). Development of TLC procedure was done for the determination of Canagliflozin. The mobile phase consisting of Toluene: Ethyl acetate: Methanol in the ratio of $2: 2: 1(\mathrm{v} / \mathrm{v} / \mathrm{v})$ culminated into favorable resolution, sharp and symmetrical peaks at $\mathrm{R}_{\mathrm{f}}$ 0.41. Linear regression data over the range of $10-500 \mathrm{ng} / \mathrm{spot}$ for Canagliflozin with a correlation coefficient of 0.9988 was unfolded by regression analysis. \% RSD for all the parameters was found to be less than $2 \%$. Percentage recovery for Canagliflozin was found within the range of 99.04-99.82\%. The LOD and LOQ values were found to be 0.39 and 1.19 respectively. The assay for Canagliflozin was found to be $99.8 \pm 0.02$. Specificity of the proposed method was confirmed when the formulation was spotted on the HPTLC plates, developed and scanned and the excipients did not interfere with the sample peak. Table 8 portrays all the standard and validation parameters along with the results obtained.

Table 8: Summary of Standard \& Validation Parameters.

\begin{tabular}{ll}
\hline Parameter & Result \\
\hline Linearity Range & $10-500 \mathrm{ng} / \mathrm{spot}$ \\
Slope & $18.042 \pm 0.001$ \\
Intercept & $735.25 \pm 0.01$ \\
Correlation coefficient & $0.9988 \pm 0.003$ \\
Intra-day Precision $(\mathrm{n}=3)$ & $0.01-0.2$ \\
Interday Precision $(\mathrm{n}=3)$ & $0.01-0.2$ \\
$\%$ Recovery $(\mathrm{n}=3)$ & $99.04 \%-99.82 \%$ \\
Limit of Detection (LOD) & 0.39 \\
Limit of Quantification (LOQ) & 1.19 \\
Specificity & Specific \\
\hline
\end{tabular}

\section{CONCLUSION}

It is found that the developed HPTLC technique is quite simple, authentic, definite, reproducible, sensitive, favorable, specific and economical. It can become efficient analytical tool for routine quality control of Canagliflozin in bulk drug and its pharmaceutical dosage forms.

\section{ACKNOWLEDGMENT}

The authors are thankful to Xi'an King smart Group Co. Limited, China for providing bulk drug sample and Johnson \& Johnson, New Delhi for providing INVOKANA ${ }^{\circledR}$. Authors are also thankful to The Director, Delhi Institute of Pharmaceutical Sciences \& Research and Dr. Sayeed Ahmed, Bioactive Natural Product Laboratory, Department of Pharmacognosy and Phytochemistry, Faculty of Pharmacy, Jamia Hamdard, New Delhi for permitting to carry out the research work.

\section{REFERENCES}

Elkinson S, Scott L. Canagliflozin: First Global Approval. Drugs, 2013; 73:979-988

International Conference on Harmonization (ICH). 2005. Validation of Analytical Procedures: Validation of Analytical Procedures: Text and Methodology Q2 (R1), Geneva.

Iqbal M, Asiri Y, Ezzeldin E, Rezk N, Rashood K,. Rapid determination of Canagliflozin in rat plasma by UHPLC-MS/MS using negative ionization mode to avoid adduct-ions formation. Talanta, 2015; $132: 29-36$

Iqbal M, Alanazi A, Khalil N, Rashood K. A simple and sensitive high performance liquid chromatography assay with a fluorescence detector for determination of Canagliflozin in human plasma. Anal. Methods, 2015; 7 : 3028-3035.

Kaur I, Singh HP, Wakode S. Development and Validation of UV Spectroscopic Method for Determination of Canagliflozin in Bulk and Pharmaceutical Dosage Form. Pharm Methods, 2015; 6(2):11 .

Neumiller JJ, Campbell RK, White JR. Sodium-glucose cotransport inhibitors: progress and therapeutic potential in type 2 diabetes mellitus. Drugs, 2010; 70(4):377-385.

Rajput DK, Patel HM, Rajput JK, Shirkhedkar AA, Surana SJ. Stability Studies of Thiocolchicoside in bulk and capsules using RPHPTLC/Densitometry. Journal of Analytical Methods in Chemistry, 2013; 1115(10): 1-7.

Singh H.P., Kaur I, Sharma G. Sodium Glucose CoTransporters-2 (SGLT2) Inhibitors as a New Class of Anti-diabetic Drugs: Pharmacokinectics, Efficacy and Clinical Significance. Int. J. Pharm. Sci. Rev. Res., 2015; 33(1): 40-47.

Skoog DA, Holler FJ, Niemen TA. 2007. Principles of Instrumental Analysis. 6th ed. Thomson Brooks/Cole. p. 762-63,816-827.

Song JC, Kaubisch S. Canagliflozin-an emerging treatment option for type 2 diabetes mellitus. Formulary Available at: $\mathrm{http} / / /$ formularyjournal.modernmedicine.com/formulary-

journal/news/user-defined-tags/canagliflozin/ Canagliflozin-emergingtreatment-option-type. Accessed: 30 November 2014.

\section{How to cite this article:}

Kaur I, Wakode S, Singh HP. Development and Validation of a Stability-Indicating High Performance Thin Layer Chromatography (HPTLC) Method for estimation of Canagliflozin in bulk and Pharmaceutical Dosage Form. J App Pharm Sci, 2016; 6 (05): 051057. 